Egyptian

Orthodontic Journal

\title{
THE EFFECT OF AZATHIOPRINE ON ORTHODONTIC TOOTH MOVEMENTS
}

\author{
ALI A. SHAMAA, BDS, MSC, PHD,* \\ YASSER L. A. MAHMOUD, BDS, MSC, PHD.**
}

\section{ABSTRACT}

The aim of the present study was to evaluate the effect of Azathioprine (Imuran) on orthodontic tooth movement. The study was conducted on thirty male white $\mathcal{N e w z e l a n d ~ r a b b i t s . ~ O r t h o d o n t i c ~}$ appliance was fixed to each rabbit to apply mesial force on the left maxillary first molar. The rabbits were then divided into two equal groups (Imuran and control groups). In the Imuran group each animal was given a daily dose of $0.5 \mathrm{mg} / \mathrm{kg} / \mathrm{BW}$ of Azathioprine (Imuran, Glaxo Wellcome, Dartfod, England) in $1 \mathrm{ml}$ solvent (0.01 $\mathcal{M} \mathcal{N a O H}$ in $0.9 \% \mathcal{N a C l}$. Each animal of the control group was given $1 \mathrm{ml}$ of the solvent as a placebo. Both groups were subdivided into three equal subgroups according to the time of evaluation; one day, one week and two weeks. At the predetermined time the maxilla was dissected. The distances of orthodontic tooth mevments were measured. Histological sections parallel to the long axis of the left maxilary first molar were prepared. The sections were stained either by H\&ZE or PAS stains. The changes in the surrounding alveolar bone were monitored. The number and activity of osteoclasts were evaluated. The results revealed that there was no significant defference between the tooth movements occured in the Imuran and control subgroups after one day $(\mathcal{P}<0.05)$. After one and two weeks, the tooth movements were significantly higher in the control subgroups than the Imuran subgroups $(\widetilde{P}>0.05)$. The histological findings showed no difference in the number and activity of osteoclasts in the pressure sides in both control and Imuran subgroups after one day $(\mathcal{P}<0.05)$. On the other hand, the number and actvity

\footnotetext{
* Lecturer, Department of Oral Biology, Menia University, Faculty of Dentistry, Egypt

${ }^{* *}$ Lecturer, Department of Orthodontics, Mansoura University, Faculty of Dentistry, Egypt
} 
Egyptian

Orthodontic Journal

\begin{abstract}
of osteoclasts were significantly higher $(\mathcal{P}>0.05)$ in the control subgroups than the study subgroups after one and two weeks. Finally, it could be concluded that; Azathioprine (Imuran) significantly retards the orthodontic tooth movement and decreases the number and activity of osteoclasts.
\end{abstract}

\title{
INTRODUCTION
}

Orthodontic tooth movement depends on alveolar bone remodeling. This highly active process involves bone formation by osteoblasts and resorption by osteoclasts. ${ }^{1}$ The osteoclasts formation process is accomplished through an orderly sequence of events that is not yet fully understood. ${ }^{2-4}$

Several factors could affect alveolar bone remodeling and hence influence the rate of tooth movement. These factors include; force magnitude and duration, age of the patient, nutrition, bone diseases and medications. ${ }^{5,6}$

In clinical practice, among patients seeking orthodontic treatment, there is group of patients who are receiving medications for a variety of systemic diseases. Medications such as bisphosphonates, fluorides, non-steroidal antiinflammatory drugs and hormones like estrogen, androgen and calcitonin may probably reduce the rate of bone resorption and consequently tooth movement..$^{5-8}$ On the other hand, corticosteroids, thyroid and parathyroid hormones increase the rate of orthodontic tooth movement via increased bone resorption. .,6,-11 $^{5}$ Since reducing orthodontic treatment time is a primary goal in orthodontics, the orthodontist should be aware of the effects of drugs on the process of tooth movement.

Azathioprine is an immunosuppressive antimetabolite drug that was originally synthesized as a pro-drug of the cytotoxic agent 6-mercaptopurine $(6-M P) .{ }^{12}$ It is usually prescribed for patients receiving solid organ transplants such as kidney, liver, heart and lung to minimize transplant rejection. ${ }^{13,14}$ It is also used for treatment of various autoimmune disorders such as rheumatoid arthritis, ${ }^{15}$ systemic lupus erythematosus, ${ }^{16}$ inflammatory bowel disease ${ }^{17}$ and nonbullous inflammatory dermatoses ${ }^{18}$. However, like all other drugs, it has several side effects. Some patients treated with Azathioprine developed bone marrow suppression, one of the most serious side effects. ${ }^{19-21}$ This bone marrow depression may adversely affect the formation of osteoclasts. Therefore this study was conducted to evaluate the effect of Azathioprin (Imuran) on the orthodontic tooth movement in rabbits. 
Egyptian

Orthodontic Journal

\section{Material and methods:}

Thirty male white Newzeland rabbits weighing 1-1.5 kg each were acclimatized for 2 weeks under experimental conditions. Their weights and general health were recorded. All animals were fed on soft laboratory diet to decrease discomfort and to avoid any harm to the orthodontic appliance.

All rabbits were anesthetized by intra-peritoneal injection of sodium thiopental` $40 \mathrm{mg} / \mathrm{kg}$ body weight. Orthodontic tooth movements were achieved in all rabbits by using closed nickel titanium coil springs* of $0.7 \mathrm{~mm}$ internal diemeter ligated with 0.010 " stainless steel ligature wire " between the maxillary left incisors and maxillary left first molars at cervical notches. The notches were made using small rose head bur to prevent the displacement of the ligature wires and the coil springs. The coil springs were ligated first to the maxillary left molars. Then they were stretched until a $50 \mathrm{gm}$ of force between the first molar and the incisor was achieved. ${ }^{22}$ This step was done with the aid of force gauge ${ }^{\star}$. Finally the other end of the coil spring was ligated to the maxillary left incisor.

The animals were divided into two equal groups. In the first group each animal was given a daily oral dose of $0.5 \mathrm{mg} / \mathrm{kg} / \mathrm{BW}$ of Azathioprine (Imuran) ${ }^{*}$ dissolved in $1 \mathrm{ml}$ solvent $(0.01 \mathrm{M} \mathrm{NaOH}$ in $0.9 \% \mathrm{NaCl}) .{ }^{12}$ While in the second group (control) each animal was given $1 \mathrm{ml}$ of the solvent as a placebo.

Both the Imuran and control groups were divided into three equal subgroups according to the predetermined times of animal sacrifice atfter one day, one week, and two weeks (Figure 1). The rabbits were decapitated then the maxillae were harvested and photographed. The distance between the distal contact point of the first molar and the mesial contact point of the second molar was measured using a Boly gauge. This distance represented the orthodontic tooth movements and was initially zero in all animals.

The tissue sample from each rabbit was fixed in $10 \%$ formalin for at least 72 hours. Specimens were then completely decalcified in 10\% EDTA for 3 weeks, dehydrated in increasing concentrations of ethanol, and embedded in paraffin. The embedded specimens were sectioned parasagittally with a rotary microtome. The speciments were sectioned parallel to the long axis of the left

^ Egyptian Int. Pharmaceutical Industries Co. (E.I.P.I.CO), Tenth of Ramadan city, Egypt.

- Dentaurum, Pforzheim, Germany

- American Orthodontics, Shebougan, USA

- Somfy tec., France

* Glaxo Wellcome, Dartfod, England 
first molars at a thickness of $7 \mu \mathrm{m}$. Ten serial sections were mounted on glass slides. Five sections were stained by Periodic Acid Schiff (PAS) stains to evaluate the osteoclast activity. ${ }^{23}$ The other five sections were stained by Hematoxylin and Eosin (H\&E) ${ }^{23}$ The number of osteoclasts in five fields per $\mathrm{H}$ $\&$ E section were counted with the light microscope $(200 \mathrm{X})$ along the mesial surfaces of the upper left first molar of the experimental and control subgroups.

The collected data was subjected to statistical analysis. Microsoft Excel program on a personal computer was used for this purpose. Mean and Standard deviation of the distance between the first and second molars and the number of osteoclasts per field were calculated for each subgroup. In addition Student t-test at 0.05 level of significance was utilized to declare the significance of differences between the Imuran and control groups.
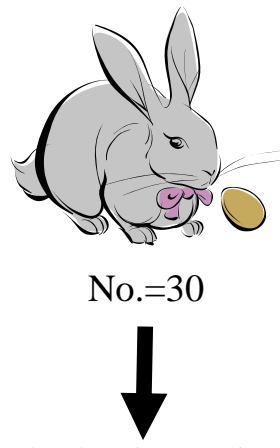

Orthodontic appliance

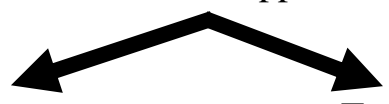

Control group

Experimental group

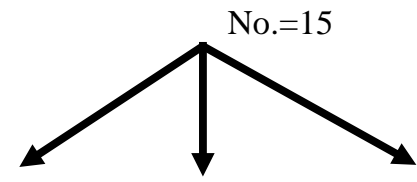

After 1day After 1week After 2 weeks

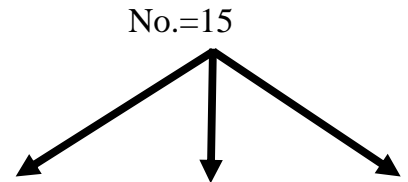

After 1day After 1week After 2weeks
No. $=5$
No. $=5$
No. $=5$
No. $=5$
No. $=5$
No. $=5$

Figure 1: Research design. 
Egyptian

Orthodontic Journal

Tooth movement (mm)

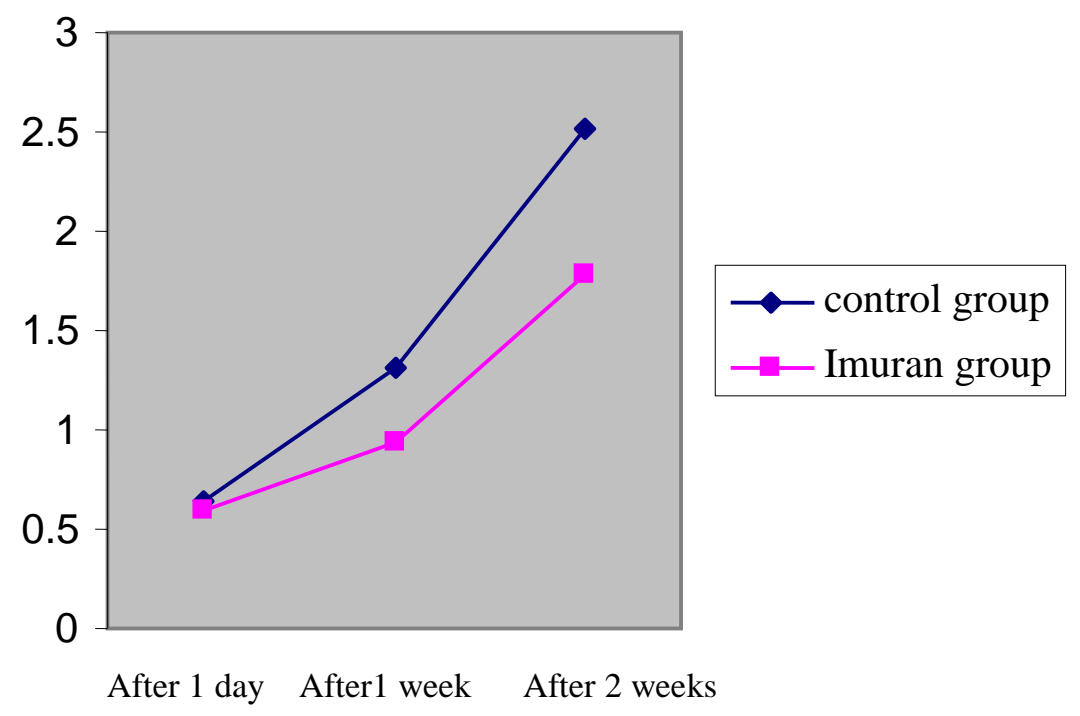

Figure 2: Orthodontic tonth movements curve

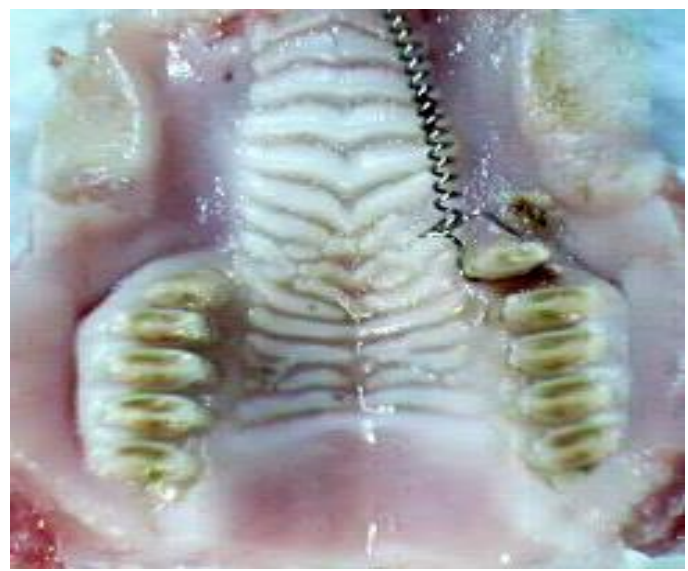

Figure 3: The increase in the distance between the upper left first and second molars (control subgroup after 2 weeks). 


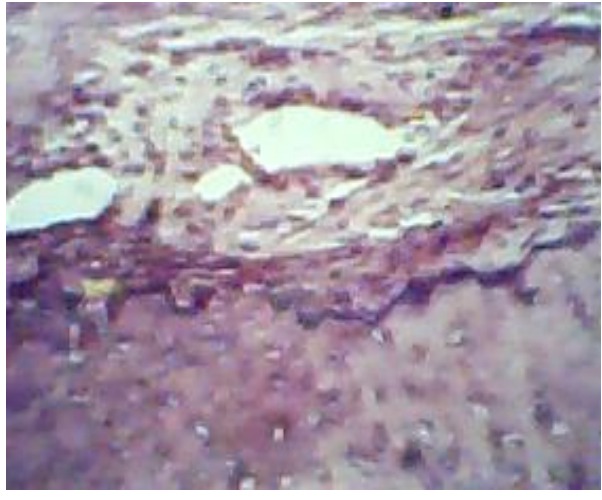

Figure 4: H\&E (200X) section of one day Imuran subgroup showing compressed periodontal ligament and decreased vas cularity in the pressure side

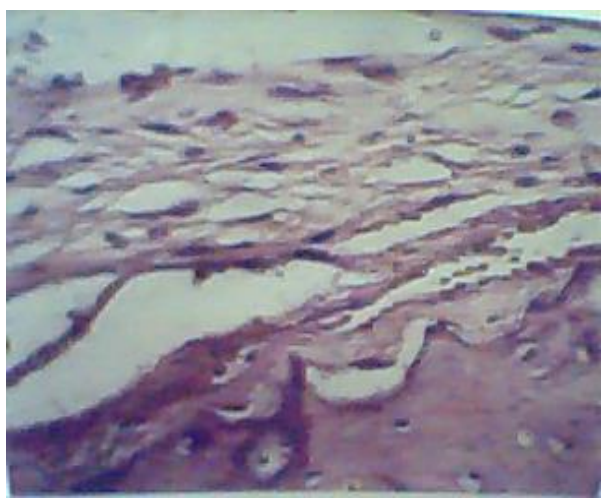

Figure 6: H\&E (200X) section of one week Imuran subgroup showing; little number of osteoclasts and eroded bone surface (Howship's lacunae) in the pressure side.

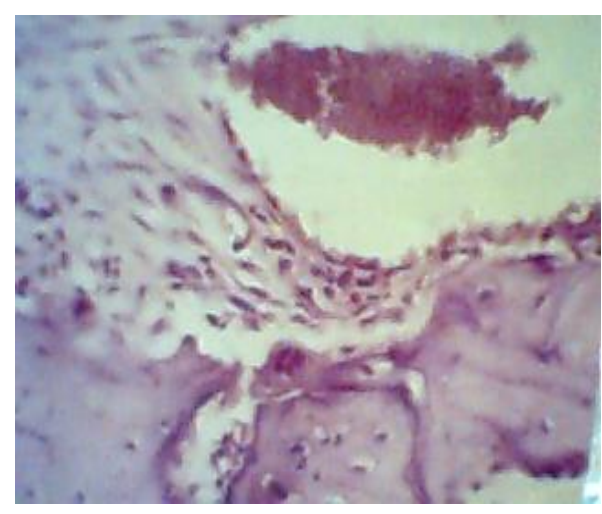

Figure 5: H\&E (200X) section in one day control subgroup showing compressed narrow periodontal ligaments with little vascularity and osteoclast cells in the pressure side

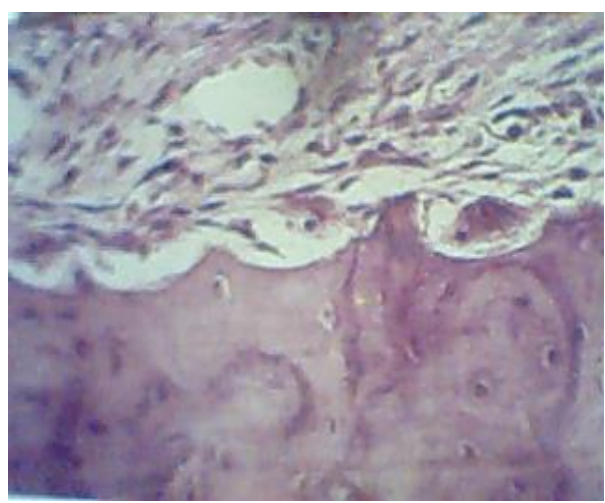

Figure 7: H\&E section (200X) of one week control subgroup showing; increased number of osteoclasts and bone resorption was evident by increased irregularity of the bone surface (Howship's lacunae) in the pressure side. 


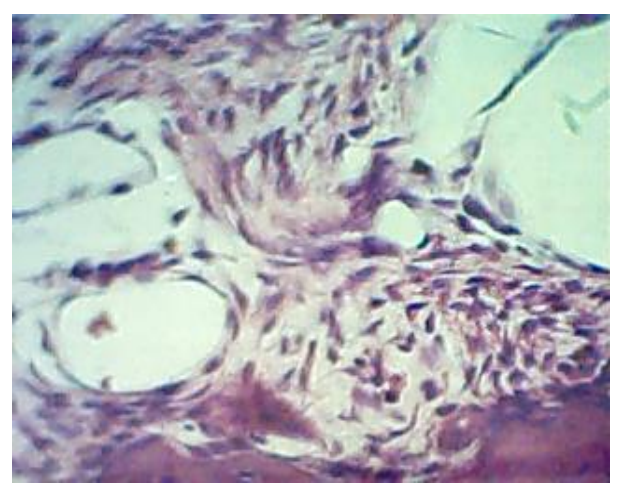

Figure 8: H\&E section (200X) of two weeks Imuran subgroup showing; little number of osteoclasts, eroded bone surface and area of bone rarefaction in the pressure side. appeared in this group.

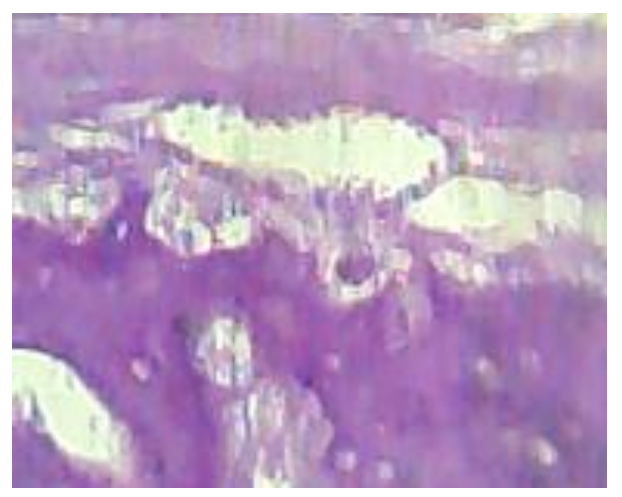

Figure 10: PAS section (200X) of two weeks control subgroup showing; PAS + ve osteoclasts in the pressure side.

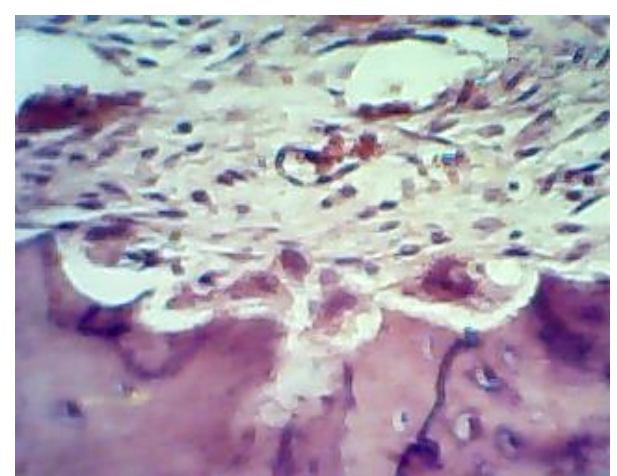

Figure 9: H\&E section (200X) of two weeks control subgroup showing; multiple osteoclasts and wide area of bone resorption and eroded bone surface.

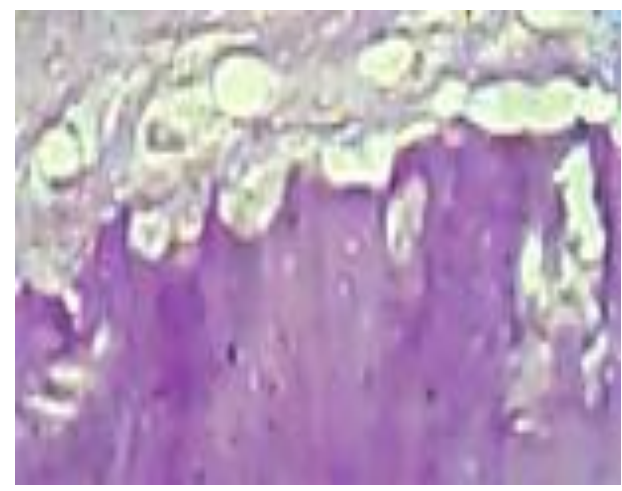

Figure 11: PAS section (200X) of two weeks Imuran subgroup showing; PAS -ve osteoclasts in the pressure side.

\section{RESULTS}

\section{Clinical findings:}

The mean and standard deviations of distances between the upper left first and second molars and the results of t-test were presented in table 1 . The distances increased in all subgroups (Figure $2 \& 3$ ). These increases were significantly higher after one and two weeks in the control subgroups than the study subgroups. On the other hand, no significant difference was found between either subgroups after one day. 
Egyptian

Orthodontic Journal

\section{Histological and histochemical findings:}

\section{I- Sections stained by H\&E:}

After one day; in Imuran and control subgroups the periodontal ligaments were narrow and compressed. The vascularity was decreased and osteoclasts were detected on the mesial side of the upper first molar "pressure side" (Figure $4 \& 5$ ). However, the number of osteoclasts was not significantly different in these two subgroups (Table 2). Distal to the first molar (tension side) there were streched periodontal ligament fibers, increased interstitial tissue spaces and osteoblasts were found along the alveolar bone surface (Figure $4 \& 5$ ).

After one week, at the pressure side in the control and Imuran subgroups there were increased number of osteoclasts, decreased vascularity and extravasated RBCs. Bone resorption was evident (Howship's lacunae) and bone surfaces specially at the alveolar bone crest were irrigular (Figure $6 \& 7$ ). However, the number of osteoclasts was significantly higher in the control subgroup than the Imuran subgroup (Table 2). The tension side showed increased cellular infiltration and vasculrity. In addition areas of osteoid tissue and osteoblasts were seen. (Figure $6 \& 7$ ).

Aftert two weeks, the pressure side showed marked increase in bone resorption and multiple osteoclasts on the bone surface with no evidence of root resorption (Figure 8\&9). However, the number of osteoclasts were significantly higher in the control subgroup than the Imuran one (Table 2). In the tension side, the osteoid tissues were more apparent with well aligned osteoblasts on the bone surface and well arranged collagen fibers (Figure 8\&9).

\section{II- Sections stained by PAS:}

There was no difference in the staining affinity of the osteoclasts in Imuran and control subgroups after one day. On the other hand, after one and two weeks of drug administration the osteoclasts exhibited deeper stained magenta coloured cytoplasm in the control subgroups as compared with the Imuran subgroups (Figure 10\&11).

Table 1: The means and standard deviations of the distances between the upper left first and second molars and the results of t-test.

\begin{tabular}{|l|c|c|c|}
\hline $\begin{array}{c}\text { Time of } \\
\text { scarification }\end{array}$ & $\begin{array}{c}\text { Control } \\
\text { subgroup } \\
\text { Mean } \pm \text { SD }\end{array}$ & $\begin{array}{c}\text { Imuran subgroup } \\
\text { Mean } \pm \text { SD }\end{array}$ & $\boldsymbol{P}$ Value \\
\hline After 1 day & $0.64 \pm 0.114$ & $0.6 \pm 0.158$ & 0.358 \\
\hline After 1 week & $1.32 \pm 0.254$ & $0.94 \pm 0.167$ & 0.005 \\
\hline After 2 weeks & $2.52 \pm 0.164$ & $1.78 \pm 0.116$ & 0.0004 \\
\hline
\end{tabular}


Egyptian

Orthodontic Journal

$\mathbf{P}>0.05$

Table 2: The means and standard deviations of the number of osteoclasts in all subgroups and the results of t-test.

\begin{tabular}{|c|c|c|c|}
\hline $\begin{array}{c}\text { Time of } \\
\text { scarification }\end{array}$ & $\begin{array}{c}\text { Control subgroup } \\
\text { Mean } \pm \text { SD }\end{array}$ & $\begin{array}{c}\text { Imuran subgroup } \\
\text { Mean } \pm \text { SD }\end{array}$ & $\boldsymbol{P}$ Value \\
\hline After 1 day & $0.8 \pm 0.836$ & $0.6 \pm 0.547$ & 0.352 \\
\hline After 1 week & $3.4 \pm 1.140$ & $1.8 \pm 0.44$ & 0.028 \\
\hline After 2 weeks & $4.8 \pm 1.303$ & $2.6 \pm 0.547$ & 0.020 \\
\hline
\end{tabular}

$\mathbf{P}>\mathbf{0 . 0 5}$

\section{DISCUSSION}

In clinical practice the orthodontist may be faced with patients who had organ transplant such as kidney. Those patients are usually under an umbrella of immunosuppressive drugs like Azathioprine (Imuran) which are essential to minimize rejection and increase the success of the implant. ${ }^{13,14}$ Imuran has been also utilized in treatment of other diseases..$^{15-18}$ Despite its well documented effects on skeletal tissues non is known about the consequences of Imuran on orthodontic tooth movements. Therefore, the present study was conducted to evaluate the effect of Imuran on the orthodontic tooth movements.

Newzeland rabbits were chosen for this study as they are calm and have considerable jaw size. All rabbits were males to avoid any hormonal effects. The orthodontic appliance consists mainly of Nitinol coil springs to provide almost constant force during the study period. Since the orthodontic appliances used applied the same force $(50 \mathrm{~g})$, the differences among Imuran and control subgroups were attributed to the Azathioprine (Imuran).

The results of the present study revealed that there was no significant difference between the tooth movements occurred in the control and Imuran subgroups after one day $(\mathrm{P}<0.05)$. The situation was changed after one and two weeks as the tooth movements were significantly higher in the control subgroups than the Imuran subgroups $(\mathrm{P}>0.05)$ as shown in table 1 .

The clinical findings were matched to the histological findings (Figure 4-9). The number of osteoclasts in the pressure sides were not significantly different in 
both and control subgroups after one day $(\mathrm{P}<0.05)$. While it was significantly higher $(\mathrm{P}>0.05)$ in the control subgroups than the study groups after one and two weeks (Table 2). The histochemical staining affinity of osteoclasts after PAS stain could be considered as an indicator for the activity of osteoclasts. After one and two weeks the osteoclasts activity was higher in the control subgroups than the Imuran subgroups (Figure $10 \& 11$ ).

The insignificant results in the present study after one day of Imuran administration could be attributed to the insufficient dose of Imuran and short duration. However, during this period tooth movements occurred in the periodontal ligament area as a result of tissue compression by orthodontic force. ${ }^{24}$

After one and two weeks Imuran had significant adverse effect on the number and activity of the osteoclasts. This could be attributed to the toxic and inhibitory effect of Imuran on the bone marrow. ${ }^{19-21}$ Hence, it could affect the quantity and quality of monocytes that are essential for the formation of osteoclasts. In addition it may affect $\mathrm{Ca}^{2+}$, cGMP and cAMP which play an important role in the differentiation of osteoclasts from monocytes in bone resorption process during orthodontic tooth movements. ${ }^{25}$, 26 More over; Imuran may have direct toxic and inhibitory effects on osteoclasts that are already present in the periodontal ligaments and alveolar bone.

The findings of the present study may have clinical relevance to the practice of orthodontics. Light orthodontic force should be used in patient receiving Imuran to avoid hyalinization and undermined resorption.

Finally, it could be concluded that; Azathioprine (Imuran) significantly retards the orthodontic tooth movement and decreases the number and activity of multinucleated giant cells (osteoclasts).

\section{REFERENCES}

1. Noxon S J, King G J, Gu G and Huang G: Osteoclast clearance from periodontal tissues during orthodontic tooth movement. Am J Orthod Dentofacial Orthop 2001;120: 466-76.

2. Rody Jr W J, King G J and Gu G: Osteoclast recruitment to sites of compression in orthodontic tooth movement. Am J Orthod Dentofacial Orthop 2001;120:477-89.

3. Ash P, Loutit J F and Twonsend $\mathrm{K}$ M: Osteoclasts derived from haematopiotic stem cells. Nature 1980;283:669-70. 
4. Tran Van P T, Vignery A and Baron R: Cellular Kinetics of the bone remodeling sequance in the rat. Anat Rec 1982; 202:445-51.

5. Shirazi M, Khosrowshahi $M$ and Dehpour A R: The effect of choronic renal insufficiency on orthodontic tooth movements in rats. Angle Orthod 2001; 71 (6): 494-98.

6. Tyrovola J B and Spyropoulos M N: Effects of drugs and systemic factors on orthodontic treatment. Quintessence Int 2001; 32(5):365-71.

7. Adachi $\mathrm{H}$, Igarashi $\mathrm{K}$, Mitani $\mathrm{H}$ and Shinoda $\mathrm{H}$ : Effects of topical administration of bisphosphonate (risedronate) on orthodontic tooth movements in rats. J Dent Res 1994;73(8):1478-86.

8. Chumbley A B and Tuncay O C: The effect of Indomethacine (an aspirin-like drug) on the rate of orthodontic tooth movement. Am J Orthod 1986; 89: 312-4.

9. Ashcraft M B, Southard K A and Tolley E A: The effect of cortecosteroidinduced osteopoosis on orthodontic tooth movement. Am J Orthod Dentofacial Orthop 1992; 102(4):310-9.

10. Kalia S, Melsen B and Verna C: Tissue reaction to orthodontic tooth movement in acute and chronic corticosteroid treatment. Orthod Craniofac Res. 2004;7 (1):26-34.

11. Shirazi M, Dehpour A R and Jafari F: The effect of thyroid hormon in orthodontic tooth movement in rats. J Clin Pediatr Dent 1999; 23(3):259-64.

12. Al-Safi S, Tashtoush B and Hassan M: Comparison of the effects of azathioprine and its novel non-mercaptopurine analog on antibody response in rabbits. Pol $\mathbf{J}$ Pharmacol 2003; 55: 239-43.

13. MacPhee I A, Bradley J A, Briggs J D, Junor B J, MacPherson S G, McMillan M A, Rodger R S and Watson M A: Long-term outcome of a prospective randomized trial of conversion from cyclosporine to azathioprine treatment one year after renal transplantation. Transplantation 1998; 66: 1186-92.

14. Oliveira J G, Monteiro M S, Teixeira J F, Osorio E, Norton S M, Alves H and Pestana M: Humoral immune responce after kidney transplantation is enhanced by acute rejection and urological obstruction and is down-regulated by mycophenolete mofetil treatment. Transpl Int. 2005; 18(11):1286-91.

15. Suarez-Almazor M E, Spooner C and Belsck E: Azathioprin for treating rhematoid arthritis. The Cochrane Database of Systemic Reviews 2000, Issue 4, Art. No.: CD001461.DOI: 10.1002/14651858. CD001461. 
16. Abu-Shakra $M$ and Shenfeld $Y$ : Azathioprine therapy for patients with systemic lupus erythematosus. Lupus 2001; 10, 152-3.

17. Fraser G, Orchard T R and Jewell D P: The efficacy of azathioprine for the treatment of inflammatory bowel disease: a 30 year review. Gut, 2002, 50, 485-89.

18. Scerri L: Azathioprine in dermatological practice. An overview with special emphasis on its use in nonbullous inflammatory dermatoses. Adv Exp Med Biol $1999 ;$ 455, 343-8.

19. Davis, Kepler A, Finger, David R, Shparago and Neal I: Dissemenated Histoplasmosis Mimiking Felty's Syndrome. J Clin Rheum 2002; 8 (1): 38-43.

20. Hibi T, Naganuma M, Kitahora T, Kinjyo F and Shimoyama T: Low-dose azathioprine is effective and safe for maintenance of remission in patients with ulcerative colitis. J Gastroenterology 2003; 38(8): 740-6.

21. Cornell W R, Kamm M A, Ritchie J K and Lennard-Jones J E: Bone marrow toxicity caused by azathioprine in inflammatory bowel disease: 27 years of experience. Gut 1993; 34: 1081-5.

22. Proffit W R, Fields H W, Ackerman J L, Sinclair P M, Thomas P M and Tulloch J F C: Contemporary Orthodontics. $2^{\text {nd }}$ Edition. 1993, Mosby-Year Book, Inc. USA.

23. Bancroft J D and Cook H C: Manual of histological technique. Churchill Livingstone 1984; P20 \& P102.

24. Shirazi M, Nilforoushan D, Alghasi $\mathrm{H}$ and Dehpour A R: The role Nitric oxide in orthodontic tooth movement in rats. Angle Orthod 2001; 72(3):211-15.

25. Igarashi K., Mitani H., Adachi H. and Shinoda H.: Anchorage and retentive effects of a bisphosphonate (AHBuBP) on tooth movement in rats. Am J Orthod Dentofacial Orthop 1994; 106:279-89.

26. King G J, Keeling S J, McCoy E A and Ward T H: Measuring dental drift and orthodontic tooth movement in response to various initial forces in adult rat. Am J Orthod Dentofacial Orthop 1991; 99:456-65. 